\title{
The role of community social capital in the relationship between socioeconomic status and adolescent life satisfaction: mediating or moderating? Evidence from Czech data
}

\author{
Thomas Buijs ${ }^{1}$, Lea Maes ${ }^{1}$, Ferdinand Salonna $2^{2^{*}}$, Joris Van Damme ${ }^{1}$, Anne Hublet ${ }^{1}$, Vladimir Kebza ${ }^{3}$,
} Caroline Costongs ${ }^{4}$, Candace Currie ${ }^{5}$ and Bart De Clercq ${ }^{1}$

\begin{abstract}
Background: The concept of social capital has been extensively used to explain the relationship between socioeconomic status (SES) and adolescent health and well-being. Much less is known about the specific mechanism through which social capital impacts the relationship. This paper investigates whether an individual's perception of community social capital moderates or mediates the association between SES and life satisfaction.

Methods: This study employs cross-sectional data from the 2009-2010 Czech Health Behaviour in School-Aged Children survey: a WHO Collaborative Cross-National Study (HBSC). A sample of 4425 adolescents from the $5^{\text {th }}$, $7^{\text {th }}$ and $9^{\text {th }}$ grade (94.5\% school response rate, $87 \%$ student response) was used to perform multilevel analysis.

Results: We found that pupils' life satisfaction was positively related to both family affluence and perceived wealth. Moreover, we found the cognitive component of social capital to be positively associated with life satisfaction. Additionally, a significant interaction was found, such that the social gradient in life satisfaction was flattened when pupils reported high levels of perceived community social capital.

Conclusions: The present findings suggest that community social capital acts as an unequal health resource for adolescents, but could potentially represent opportunities for public health policy to close the gap in socioeconomic disparities.
\end{abstract}

Keywords: Health inequalities, Social capital, Life satisfaction, Youth, Czech Republic

\section{Background}

Social inequalities are an important public health topic concerning the entire population [1]. Differences in health outcomes do not only exist between the lowest and highest socioeconomic classes, but follow a gradient pattern [2, 3]. Regarding adolescents, a large body of evidence documents the relationship between social inequalities and health [4]. Moreover, recent time-series analysis has shown that socioeconomic inequalities in adolescent health have increased from 2002 to 2010 in 34 North American and European countries [5]. Targeting

\footnotetext{
* Correspondence: ferdinand.salonna@upol.cz

${ }^{2}$ Institute of Active Lifestyle, Faculty of Physical Culture, Palacky University in Olomouc, Tr. Miru 15, Olomouc 77111, Czech Republic

Full list of author information is available at the end of the article
}

young people and their communities is fundamental because (1) social inequalities pass across generations [1] and (2) what happens throughout childhood is likely to have a life-long impact [6] since virtually every aspect of early human development (physical, cognitive, and socioemotional) is sensitive to external influences $[4,7,8]$. Traditional policy interventions, focusing on individuals' attributes, knowledge and skills have been shown to merely produce limited effects [9], whereas ample research on the other hand has shown that young people's health and well-being is shaped, not only by personal decisions, but also by the routine organization of everyday settings like neighborhoods, communities, schools and other social networks [10-12]. It is in this context that social capital emerged as a prominent concept in public 
health to explain the relationship between socioeconomic status (SES) and people's health and well-being and to suggest policy options [13]. This has led to the incorporation of social capital into the WHO's general conceptual framework on the social determinants of health [14]. Social capital and initiatives that increase cohesion, co-operation and interpersonal trust, can play an important role in decreasing socioeconomic inequalities between adolescents with low and high SES, thus effectively flattening the social gradient. Evidence shows that health gains incurred by increasing social capital are particularly marked for disadvantaged (or vulnerable) children and young people in communities with low social capital $[15,16]$. Much less is known however on the specific mechanism, i.e. mediating versus moderating, through which social capital operates. Nevertheless, this is a crucial aspect for policy makers in order to transform existing research into policy. Moreover, any discussion on social inequalities in health and social capital has to be framed within the concept of the welfare regime theory [17]. As such, analyzing Czech data provides a unique case since research in Central and Eastern European welfare countries remains limited to date.

\section{Social capital: conceptual review}

Since its introduction, social capital has been variously defined, from being an individual resource embedded in social relations $[18,19]$ to "features of social organization such as networks, norms, and social trust that facilitate coordination and cooperation for mutual benefit" ([20], p.67). Orthogonal to the distinction between "individual" and "collective" social capital, most conceptualizations can be decomposed into a structural and a cognitive component $[21,22]$. Structural social capital refers to objectively measurable characteristics such as participation in clubs, neighborhood activities and other social networks. Cognitive social capital refers to the perception of level of trust and reciprocity, through norms, values and attitudes. Within the structural component of social capital, an important distinction is made between bonding, bridging and linking components, which respectively refer to connections between people of similar social groups, different social groups and links with external sources of power [23, 24].

Despite the lack of agreement in terms of a clear definition for social capital more than three decades after the reintroduction of social capital by Bourdieu, Coleman and Putnam, it is hard not to be impressed with the overwhelming evidence indicating that social capital is an important determinant of major health outcomes (e.g. [17, 24-32]).

\section{Life satisfaction, health and social capital}

Subjective well-being (SWB) is an important topic within public health research. A growing body of research evidence shows significant associations between high subjective well-being and positive health outcomes such as positive adolescent development [33-35], decreased suicide rates [36] and increased health and longevity [37]. Research in the field of positive psychology recognizes three distinct categories that compose SWB: emotional responses (positive affect: joy, optimism, negative affect: sadness, anger), domain satisfactions (such as work satisfaction or relationship satisfaction) and life satisfaction [38], all three of which are commonly used to measure SWB interchangeably. Though little empirical research has been conducted to differentiate these heterogeneous aspects of SWB thus far, scientific consensus is that life satisfaction, i.e. a subjective evaluation of the overall quality of life, is the most stable indicator and therefore the key indicator when studying links between SWB and health outcomes [37]. The concept of life satisfaction is of specific interest when studying inequalities in adolescent health, considering the formative nature of this life stage and thus its significant impact on health outcomes later in life [4]. Research has shown clear links between life satisfaction and physical activity [39, 40], substance use [41-43] and unhealthy diet [44]. Moreover, previous research has shown that life satisfaction is unevenly distributed between adolescents with low and high SES $[45,46]$. As such, researching social capital in relation to adolescent life satisfaction is meaningful in order to identify opportunities for policy makers to reduce socioeconomic inequalities and improve the health of low SES adolescents. Recently, several studies have investigated the cross-sectional relationship between social capital and life satisfaction using the Cantrill ladder [47], a reliable and valid instrument, using relatively simple self-rating questions about life satisfaction and more generally, happiness [48-50]. Most research studies so far have found a positive relationship between social capital and life satisfaction [12, 51, 52].

In the context of community social capital, which is analyzed in this paper, the preponderance of the evidence suggests that adolescents with a wider range of (or higher quality of) social support networks, benefit through better general health, quality of life and life satisfaction. The most complete literature review to date included 39 research papers that studied the effect of community social capital on life satisfaction; 26 studies showed a positive relation and 13 showed no relation, whereas not a single study found a negative relation [12]. Specifically school $[16,53-55]$ and neighborhood environments $[15,56,57]$ were found to be beneficial in promoting better outcomes.

\section{Mediating/moderating: empirical evidence}

Limited research is available on the nature of the social capital mechanism, that is to say whether social capital moderates or mediates the relationship between socioeconomic position and life satisfaction. Nevertheless, the mechanism 
through which community social capital influences life satisfaction is highly important for policy makers. A mediating, or indirect relation, implies that a third variable underlies an observed relationship between two variables [58]. This would mean that high SES leads to higher community social capital, which would in turn lead to higher life satisfaction. A moderating, or direct relationship, on the other hand, implies that a third variable directly influences the relationship between two other variables $[58,59]$. This would mean that community social capital directly impacts the relation between SES and life satisfaction. It is obvious that the latter scenario is to be preferred by policy makers as it would allow them to employ community social capital as a health resource.

Moreover, most of the available research focuses on health, rather than well-being. In an individual-level study on the psychosocial pathway of health inequalities, Veenstra [60] found only little evidence for the individual effects of social capital on self-rated health status and no evidence for a mediating mechanism. However, these findings should be treated with caution given some serious limitations such as a small sample size $(n=534)$ and low response rate $(40 \%)$. After a decade of social capital research, a similar study was set up by Dahl [61] hypothesizing that individual social capital may mediate the impact of socioeconomic position on health. However, the results of the study did not confirm this expectation for health outcomes as perceived health and longstanding illness. In contrast to this finding, the results of Lindström et al. [62] support the idea that social capital is an important mediating link behind the socioeconomic differences in leisure-time physical activity and, ultimately, cardiovascular diseases. Few studies on social capital and health inequalities studied outcomes in children. In a recent review on neighborhood social capital and the gradient in adolescent health, Vyncke et al. [63] found a total of eight studies, of which just two found evidence for a mediating social capital mechanism for respectively mental health problems [64] and verbal ability and behavioral problems [65]. Since the evidence for a mediating mechanism of social capital in the individual relationship between socioeconomic position and (child) health, is inconclusive, the present study hypothesizes that the psychosocial mechanism of social capital may be a moderating one. In line with others who demonstrated a moderating social capital mechanism for internalizing and externalizing behavioral [66] and antisocial behavioral problems [67]. In a sample of young children and adolescents, the authors already found evidence for a moderating effect of community social capital at the contextual level on adolescent perceived health and wellbeing [15]. Others [68] also found evidence for a moderating effect of community social capital at the individual level for a variety of outcomes. They demonstrated that social capital nullified SES effects on psychological symptoms and life satisfaction and narrowed SES differences in somatic symptoms, injuries and fighting. Similar findings were reported for community social capital at the contextual level [15].

\section{Welfare regime theory: a brief introduction}

The protective effect of social capital on health inequalities may not be invariant for national contexts since different welfare regimes may modify the impact of both social inequality [69,70] and social capital [17] (see Eikemo and Bambra [71] for an introduction to welfare regime theory). More specifically for adolescents, Richter et al. [72] found that regime type contributed to the explanation of cross-national variations in adolescent self-rated health and health complaints, but for social inequalities in health they could not find a clear pattern between welfare regime types. Regarding to social capital, Islam et al. [17] argue that the influence of social capital might be less salient in egalitarian countries (defined by comparatively low levels of income inequality and strong welfare states). Yet, recent studies in typical egalitarian countries like Norway [73] and Japan [74] reveal substantial differences in social capital and associations with health outcomes. In general, the protective effect of social capital on health inequalities was examined mainly in Anglo-Saxon (liberal) countries (e.g. $[60,66-68])$, and more recently also in countries representing the Bismarckian (conservative) (e.g. [15]) and Scandinavian (social democratic) welfare regime types (e.g. [61]), but much less is known about the situation in Eastern and Central European welfare countries such as Slovakia, Poland, Hungary and the Czech Republic. After the breakdown of their communist regimes they are still undergoing extensive social reforms and should be treated as a distinctive regime type [75].

\section{Aim}

The objectives of this research are to investigate whether an individual perception of community social capital moderates or mediates the association between SES and adolescent well-being. Life satisfaction was used as outcome measure [47]. In accordance with Dahl [61], we conceptualize community social capital as it empirically appears at the individual level only. In addition, the present study investigates data from the Czech Republic being a unique case for the interrelationships between social inequality and social capital because (1) evidence suggests that social capital plays a comparatively smaller role in egalitarian countries [17] and (2) despite similar Gini coefficients ${ }^{1}$ [76] the historical and socio-political context is significantly different from other egalitarian countries characterized by the well-known Nordic welfare model [77-81]. 


\section{Methods \\ Sample}

Cross-sectional data from the 2009-2010 survey of Czech Health Behaviour among School-aged Children, was used. This survey is part of the international Health Behaviour in School-Aged Children survey: a WHO Collaborative Cross-National Study (HBSC) [82]. The aim of the HBSC study is to describe young people's health and health behavior, and to analyze how these outcomes are associated with social contexts. Self-completion questionnaires were administered in school classrooms, with requirements in terms of sampling, questionnaire items and survey administration being set out in a standardized research protocol [83]. All of the questions used in the HBSC survey must have evidence of reliability and validity when used in multiple countries before they are considered for inclusion. From a list of schools, based on information from the Institute for Information on Education, a contributory organization of Ministry of Education, Youth and Sport, 91 schools from all 14 regions of the Czech Republic were randomly selected to create a representative sample. 86 schools took part in the survey, representing a $94.5 \%$ school response rate. According to the protocol of the HBSC study classes from the 5th to 9th grades were selected randomly, one from each grade per school. According to the international research protocol, set forward by HBSC [82], data were obtained from 5284 adolescents from the 5th, 7th and 9th grade of elementary schools in the Czech Republic (response: 87\%). Nonresponse due to absence was $13 \%$.

Participation in the study was fully voluntary and anonymous with no explicit incentives provided for participation. The questionnaires were administrated by trained research assistants in the absence of a teacher during regular class time. Parents were informed about the study from the school administration and could opt out if they disagreed. Data collection was done under the principles of the Declaration of Helsinki and legal and regulatory requirements applicable in the Czech Republic.

For the purpose of this paper adolescents of 11 years $(n=1426), 13$ years $(n=1456), 15$ years $(n=1522)$ are included. The final sample consists of 4425 Czech pupils (49\% boys).

\section{Dependent variable}

Life satisfaction is measured by the following question: 'How happy would you say you are with your life?' [47]. This variable consists of a discretionary 10-item numerical response ladder (range $1=$ worst possible life $-10=$ best possible life).

\section{Independent variables}

This study applies two different indicators for SES, both reflecting different aspects: Family affluence is an indicator of absolute wealth [84]. The family affluence scale (FAS) is a composite indicator of self-reported socioeconomic status comprising four items that address family assets or conditions that indicate material wealth: 'Does your family own a car, van or truck? $(0=$ no; $1=$ yes one; $2=$ yes two or more); Do you have your own bedroom? $(0=$ no; 1 = yes); During the past 12 months, how many times did you go on holiday with your family? $(0=$ not at all, $1=$ once, $2=$ twice, $3=$ more than twice); How many computers does your family own?' $(0=$ none, $1=$ one, 2 =two, $3=$ more than two). Responses are summed on a 1 to 10 scale with higher scores indicating greater affluence. From its early development, there have been efforts to validate the family affluence scale at both national and international levels [85]. There is a strong agreement between children's reports on family affluence scale items and their parents' report [86].

The perceived wealth indicator reflects the concept of relative wealth and is measured using the following question: 'How well off do you think your family is?' $(0=$ not at all well off; $1=$ not very well off; $2=$ average; 3 = quite well off; 4 = very well off).

Measures of social capital, measured at the individual level, are employed, using the decomposition between a structural and a cognitive component (Baum \& Ziersch [21]; Harpham et al., [22]). Structural social capital is measured by the participation in clubs: 'Are you involved in any of these kinds of clubs or organizations?' Response categories: sports club, voluntary service, political organization, cultural organization, church or religious group, youth club, other club ( $0=$ no, $1=$ yes). An unweighted sum score was calculated (range $0-7$ ). Cognitive social capital is measured using a 5-item scale [87]: 'People say 'hello' and often stop to talk to each other in the street; it is safe for younger children to play outside during the day; you can trust people around here; there are good places to spend your free time; I could ask for help or a favor from neighbors (1 = strongly disagree, 2 = disagree, $3=$ neither agree nor disagree, $4=$ agree, $5=$ strongly agree). An exploratory factor analysis was performed, using Mplus 7.11 [88] to determine whether all included items load onto a unique factor or not. The EFA entails that an oblique rotation of factors was performed allowing factors to co-vary. Values below 0.05 on the Root Mean Square Error of Approximation (RMSEA) and a value of 0.90 or greater on the Comparative Fit Index (CFI) were considered as indicative of a good fit. The results showed that all items load onto a unique factor (results available from the authors).

\section{Analysis}

Multilevel modeling is employed using MLwiN software (version 2.32) to account for the hierarchical structure of 
the data, i.e. non-random clustering of pupils in classes and schools $[89,90]$. All models are three-level random intercept models including variables on level 1 only and with no random slopes. Level 1 units in our sample are pupils $(n=$ 4425), level 2 units are classes $(n=246)$, and level 3 units are schools $(n=86)$. Models are calibrated using the Maximum Likelihood procedure which utilizes the (Restricted) Iterative Generalized Least Squares algorithm [91].

First, an empty model (intercept-only) with no explanatory variables was estimated in order to decompose the variance of the intercept into variance components for each of the three levels. The variation by class and school was expressed as intraclass correlation coefficient (ICC). This model is useful as a null model that serves as a benchmark with which other models are compared (Model 1). Model 2 includes the socio-demographic variables as covariates. In a third step, a model with individual socioeconomic predictors, namely, family affluence (absolute indicator) and perceived wealth (relative indicator) is conducted (Model 3). Structural social capital and cognitive social capital are added as explanatory variables in Model 4. This model estimates the contribution of both the structural and the cognitive component of social capital to life satisfaction.

In order to assess the moderating association between social capital and social inequalities in health, a similar approach as De Clercq et al. [15] is used. Interaction terms are estimated between both SES indicators and both components of social capital (Model 5a-d). To test the improvement of fit for each model, -2log-likelihood deviance values are calculated [90]. The conventional 5\% level is used to determine statistical significance. In order to measure if social capital provides a mediating mechanism between SES and life satisfaction, the product a $\mathrm{x} b$ was tested for significance using bootstrapped standard errors. This product covers the effect of SES (i.e. family affluence or perceived wealth) on a mediator (i.e., structural or cognitive component of social capital) multiplied by the effect of a mediator on life satisfaction, controlled for SES [92]. Significance was tested using the Sobel test [93].

\section{Results}

\section{Descriptive results}

Table 1 includes descriptive statistics of the variables used in the analysis. Respondents $(n=4425)$ are divided into three age groups (11, 13 and 15 years old) and hierarchically clustered within classes $(n=246)$ and schools $(n=86)$. Both boys and girls are proportionally distributed in the overall sample.

\section{Multivariate associations: SES, social capital and life satisfaction}

Table 2 presents the results of four successive multilevel models. The first model shows that $3,7 \%$ of the observed
Table 1 Descriptive statistics over variables related to sociodemographic background, socioeconomic status, social capital and life satisfaction

\begin{tabular}{|c|c|c|}
\hline \multicolumn{3}{|l|}{ Socio-demographics } \\
\hline \multicolumn{3}{|l|}{ Gender } \\
\hline Boy & $\%$ & 48.5 \\
\hline Girl & $\%$ & 51.5 \\
\hline \multicolumn{3}{|l|}{ Age } \\
\hline 11 & $\%$ & 32.2 \\
\hline 13 & $\%$ & 32.9 \\
\hline 15 & $\%$ & 34.4 \\
\hline \multicolumn{3}{|l|}{ Socio-economics } \\
\hline Family affluence & $\begin{array}{l}\text { Mean-mode (s.d.), } \\
\text { range }=1-10\end{array}$ & $6.32-6(1.75)$ \\
\hline Perceived wealth & $\begin{array}{l}\text { Mean-mode (s.d.), } \\
\text { range }=1-5\end{array}$ & $3.33-3(0.78)$ \\
\hline \multicolumn{3}{|l|}{ Social capital } \\
\hline Structural social capital & $\begin{array}{l}\text { mean-mode (s.d.), } \\
\text { range }=0-7\end{array}$ & $1.40-1(1.26)$ \\
\hline Cognitive social capital & $\begin{array}{l}\text { mean-mode (s.d.), } \\
\text { range }=1-5\end{array}$ & $3.69-3(0.68)$ \\
\hline Life satisfaction & $\begin{array}{l}\text { mean }(\text { s.d.), } \\
\text { range }=1-10\end{array}$ & $7.49(1.84)$ \\
\hline
\end{tabular}

variance in life satisfaction is at the class level while no variance is observed at the school level. The grand mean is 7.499 (range $1-10$ ). This is the average life satisfaction for all respondents $(n=4425)$ within all classes $(n=$ $246)$ and schools $(n=86)$. The second model shows that the socio-demographic variables are significantly associated with pupils' life satisfaction: girls and older adolescents report lower levels of life satisfaction $(p<0.01)$. After taking into account these individual sociodemographic factors, the amount of class variance was significantly reduced: about half of the class level variance in life satisfaction is attributable to the gender and age composition of the classes. Model 3 accounts for the SES indicators. We observe a significant social gradient in the relationship between socioeconomic position and life satisfaction. More precisely, pupils' life satisfaction is positively related to both family affluence and perceived wealth $(p<0.01)$, but the relative indicator (perceived wealth) is a much stronger determinant for life satisfaction than the absolute indicator (family affluence). Adding the SES indicators turned the effect of gender non-significant. In model 4 we added the social capital variables. Only the cognitive component of social capital is positively associated with life satisfaction $(p<0.01)$. There is no statistically significant effect of structural social capital. Overall, the associations in the fourth model did not substantially change from the third model. Moreover, the effect of cognitive social capital did not 
Table 2 Fixed and random parameters of the three-level life satisfaction model

\begin{tabular}{|c|c|c|c|c|c|c|c|c|}
\hline & \multicolumn{2}{|l|}{ Model 1} & \multicolumn{2}{|l|}{ Model 2} & \multicolumn{2}{|l|}{ Model 3} & \multicolumn{2}{|l|}{ Model 4} \\
\hline & $B$ & (S.E.) & $B$ & (S.E.) & $B$ & (S.E.) & $B$ & (S.E.) \\
\hline \multicolumn{9}{|l|}{ Fixed effects } \\
\hline Constant & 7.499 & $(0.036)^{* * *}$ & 7.900 & $(0.064)^{* * *}$ & 7.799 & $(0.063)^{* * *}$ & 7.725 & $(0.060)^{* * *}$ \\
\hline \multicolumn{9}{|l|}{ Individual-level } \\
\hline \multicolumn{9}{|l|}{ Socio-demographics } \\
\hline Female & & & -0.201 & $(0.056)^{* *}$ & -0.092 & $(0.054)^{n . s .}$ & -0.073 & $(0.053)^{\text {n.s. }}$ \\
\hline \multicolumn{9}{|l|}{ Age (ref: 11) } \\
\hline 13 & & & -0.312 & $(0.079)^{* *}$ & -0.295 & $(0.077)^{* *}$ & -0.245 & $(0.073)^{* *}$ \\
\hline 15 & & & -0.548 & $(0.078)^{* *}$ & -0.439 & $(0.076)^{* *}$ & -0.304 & $(0.074)^{* *}$ \\
\hline \multicolumn{9}{|l|}{ Socioeconomics } \\
\hline Family affluence & & & & & 0.096 & $(0.016)^{* *}$ & 0.077 & $(0.016)^{* *}$ \\
\hline Perceived wealth & & & & & 0.538 & $(0.037)^{* *}$ & 0.446 & $(0.036)^{* *}$ \\
\hline \multicolumn{9}{|l|}{ Social capital } \\
\hline Structural social capital & & & & & & & 0.033 & $(0.021)^{\text {n.s. }}$ \\
\hline Cognitive social capital & & & & & & & 0.689 & $(0.041)^{* *}$ \\
\hline \multicolumn{9}{|l|}{ Class-level } \\
\hline \multicolumn{9}{|l|}{-} \\
\hline \multicolumn{9}{|l|}{ School-level } \\
\hline \multicolumn{9}{|l|}{-} \\
\hline \multicolumn{9}{|l|}{ Random effects } \\
\hline Individual-level variance & 3.253 & $(0.072)^{* * *}$ & 3.250 & $(0.073)^{* * *}$ & 3.002 & $(0.067)^{* * *}$ & 2.813 & $(0.064)^{* * *}$ \\
\hline Class-level variance & 0.124 & $(0.028)^{* *}$ & 0.058 & $(0.028)^{*}$ & 0.057 & $(0.026)^{*}$ & 0.047 & $(0.024)^{*}$ \\
\hline School-level variance & 0.000 & $(0.000)^{\text {n.s. }}$ & 0.009 & $(0.018)^{n . s .}$ & 0.011 & $(0.017)^{n . s .}$ & 0.005 & $(0.015)^{\text {n.s. }}$ \\
\hline Log likelihood & 17281.1 & & 17156.0 & & 16611.4 & & 16112.9 & \\
\hline$\Delta$ Log likelihood ( $\Delta \mathrm{df}$ ) & & & $125.1(3)$ & & $544.6(2)$ & & $489.5(2)$ & \\
\hline$p$ & & & $<.001$ & & $<.001$ & & $<.001$ & \\
\hline
\end{tabular}

Figures in parentheses represent standard errors

n.s. not significant

${ }^{*} p<0,05,{ }^{* *} p<0,01,{ }^{* * *} p<0,001$

explain away the relationship between SES indicators and life satisfaction.

\section{Interaction terms: Does social capital modify social inequalities in life satisfaction?}

Table 3 presents the results of four multilevel models that investigate all possible interactions between both the relative and absolute SES measures and both components of social capital. Model 5a-c were not interpretable since their deviance statistic was not significant, indicating that these models did not fit the data better than the more simple model 4 . The final model $5 \mathrm{~d}$ examines the interaction between perceived wealth and cognitive social capital $(p<0.01)$. Figure 1 plots the predicted relationship between perceived wealth and life satisfaction for low and high levels of cognitive social capital, indicating that the social gradient in life satisfaction was leveled-up when pupils reported a high level of cognitive social capital.
Looking for a potential mediating effect, we observed a significant direct relation between family affluence and perceived wealth, and life satisfaction (Table 2, Model 3). Both, family affluence and perceived wealth significantly affected structural and cognitive social capital (a-path) (Table 4), which in turn significantly affected life satisfaction (b-path) (Table 2, Model 4). Looking at the indirect effects, only cognitive social capital was found to be a significant mediator of both relations between SES and life satisfaction (Table 4).

\section{Discussion}

In the last fifteen years researchers and policy makers have paid increasing attention to the concept of social capital as a major topic for public health [94-96]. The aim of the present study was to investigate whether an individual perception of community social capital moderates or mediates the association between SES and adolescent 
Table 3 Interaction terms of the life satisfaction model

\begin{tabular}{|c|c|c|c|c|c|c|c|c|}
\hline & \multicolumn{2}{|c|}{ Model 5a } & \multicolumn{2}{|c|}{ Model 5b } & \multicolumn{2}{|c|}{ Model 5c } & \multicolumn{2}{|c|}{ Model 5d } \\
\hline & B & (S.E.) & B & (S.E.) & B & (S.E.) & B & (S.E.) \\
\hline \multicolumn{9}{|l|}{ Fixed effects } \\
\hline Family affluence $x$ structural social capital & 0.003 & $(0.011)$ & - & & - & & - & \\
\hline Family affluence $x$ cognitive social capital & & & -0.017 & $(0.022)$ & - & & - & \\
\hline Perceived wealth $x$ structural social capital & & & & & 0.037 & $(0.025)$ & - & \\
\hline Perceived wealth $x$ cognitive social capital & & & & & & & -0.204 & $(0.045)^{* *}$ \\
\hline \multicolumn{9}{|l|}{ Random effects } \\
\hline Individual-level variance & 2.813 & $(0.064)$ & 2.813 & $(0.064)$ & 2.811 & $(0.064)$ & 2.799 & $(0.063)^{* * *}$ \\
\hline Class-level variance & 0.048 & $(0.024)$ & 0.047 & $(0.024)$ & 0.047 & $(0.024)$ & 0.046 & $(0.024)^{n . s}$ \\
\hline School-level variance & 0.005 & $(0.015)$ & 0.005 & $(0.015)$ & 0.005 & $(0.015)$ & 0.007 & $(0.015)^{\mathrm{n} . \mathrm{s}}$ \\
\hline Log likelihood & 16112.8 & & 16112.3 & & 16110.6 & & 16092.1 & \\
\hline$\Delta$ Log likelihood $(\Delta \mathrm{df})$ & $0.1(1)$ & & $0.6(1)$ & & $2.3(1)$ & & $20.8(1)$ & \\
\hline$p$ & 0.751 & & 0.438 & & 0.219 & & $<.001$ & \\
\hline
\end{tabular}

Figures inn parentheses represent standard errors

Model 4 was the control and reference model for $\Delta$ Log likelihood ( $\Delta$ df) calculations of Model $5 a-d$

n.s. not significant

** $p<0,01$, *** $p<0,001$

life satisfaction. Previous studies have demonstrated a moderating mechanism both at the contextual $[15,66,67]$ and individual level [68].

The results from the multivariate interaction models partly confirmed this expectation. Only one of the four interaction models (Model $5 \mathrm{~d}$ ) showed significant fit to the data, indicating that the association between perceived wealth and life satisfaction was moderated by cognitive social capital. Research looking at a mediating mechanism has been mixed with most studies showing little evidence [60-62]. However, in this study results from the Sobel test showed that cognitive social capital is a significant mediator in the relationship between life satisfaction and both FAS and perceived wealth.
Our findings add to the existing knowledge in five ways. Firstly, the study differentiated between the two main components of social capital [21, 22]: the structural component and the cognitive component. Previous studies emphasized the importance of this differentiation since each component may be associated differently with health and well-being [97, 98]. Results from our mutually adjusted model (Model 4) showed that cognitive social capital was positively and independently associated with adolescent life satisfaction while the association with structural social capital was not significant. Although not entirely in line with previous research, the absence of a significant association between the structural component of social capital and adolescent life satisfaction does not

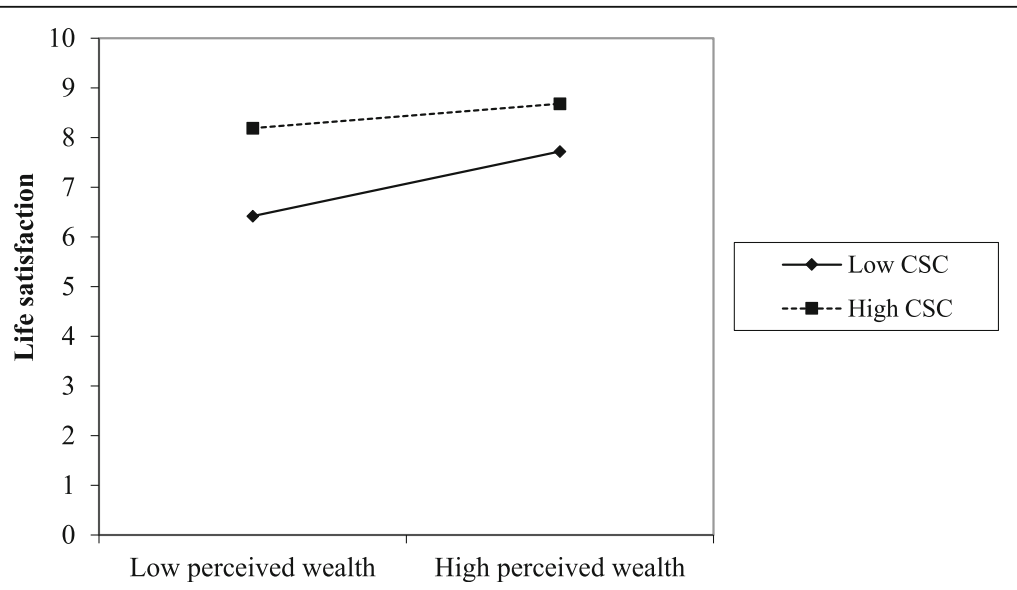

Fig. 1 Predicted relationship between perceived wealth and life satisfaction for low and high level of community social capital (CSC) based on the fixed part results from Model $5 d(p<0.01)$ 
Table 4 Indirect effects and a-paths of the life satisfaction model

\begin{tabular}{|c|c|c|c|c|}
\hline & \multicolumn{2}{|c|}{ ab-path } & \multicolumn{2}{|c|}{ a-path } \\
\hline & B & (S.E.) & B & (S.E.) \\
\hline Family affluence $>$ structural social capital > life satisfaction & 0.003 & $(0.002)^{\text {n.s. }}$ & 0.080 & $(0.011)^{* * *}$ \\
\hline Family affluence > cognitive social capital > life satisfaction & 0.014 & $(0.004)^{* * * *}$ & 0.020 & $(0.006)^{* * *}$ \\
\hline Perceived wealth > structural social capital > life satisfaction & 0.003 & $(0.002)^{\text {n.s. }}$ & 0.083 & $(0.026)^{* *}$ \\
\hline Perceived wealth > cognitive social capital > life satisfaction & 0.100 & $(0.011)^{* * *}$ & 0.145 & $(0.013)^{* * *}$ \\
\hline
\end{tabular}

come as a complete surprise for two reasons. Firstly, our results confirm a more recent study that investigated the relationship between social capital and self-rated wellbeing in Europe. While measures of structural social capital were significant for the full sample, decomposition into geographical subgroups showed that this association was mainly driven by Western-Europe, whereas the relationship was much weaker in Eastern-Europe (including the Czech Republic), where several of the indicators were insignificant [99]. The authors concluded that it seems as if local culture, social institutions, customs and traditions drive the strength of social capital linkages to life satisfaction in different parts of Europe. More research is needed however to confirm this claim. More broadly, the lack of association between structural social capital and adolescent life satisfaction can be viewed in the ongoing debate on the importance of absolute affluence versus relative inequality. Previous research has indicated that as countries reach a certain GNP per capita (typically 10,000-13,000), the effect of relative inequality becomes increasingly important $[100,101]$. Recent research, using HBSC data, has also been shown to be in line with this hypothesis [102]. Secondly, the present study offered some evidence to support the validity of the social cohesion and collective social pathway theory [103], linking individual socioeconomic status (SES) to well-being. More specifically, we found evidence for both the moderating and the mediating variant. This finding is in line with Elgar et al. [68], but contradicts the results found in Dahl et al. [61]. Thirdly, a moderating effect of social capital opens new perspectives for health promotion since such a mechanism implies that social capital may be a way to decrease socioeconomic inequalities between adolescents with low and high SES, thus effectively flattening the social gradient in health. A mediating mechanism would imply that one's socioeconomic position affects the availability and allocation of social capital as a health asset. In contrast, a moderating mechanism allows people to address health assets regardless of their personal characteristics. Note that neo-materialist explanations will still consider this as a 'workaround solution', arguing that interpretations should start with the structural and material causes of inequalities rather than with perceptions of inequality [104]. Either way, our findings emphasize the need for more research on mediating and moderating mechanisms in order to understand the relation between SES and young people's life satisfaction. Fourthly, the present results are discussed in the light of the welfare regime theory $[69,70]$. Of course, only comparative studies can make statements about variability in social inequality and social capital between countries, but our results do indicate that both matter in the Czech context: (1) relative and absolute SES indicators were both positively and independently related to adolescent life satisfaction, and (2) cognitive social capital was positively related to adolescent life satisfaction. The findings on social inequality in adolescent life satisfaction were not surprising. Mackenbach [105] reviews nine theories that may potentially explain such persisting and even widening social inequalities. The author concludes that the psychosocial theory cannot explain the widening of social inequalities, but may explain why social inequalities persist. Despite the welfare state, considerable differences in power and prestige have continued to exist. Some of the inequalities in psychosocial stress may have blurred, but the middle classes have also benefited from the welfare state, for example because it has reduced the psychosocial stress of job insecurity even among the employed [106]. Moreover, advanced welfare states may raise unrealistic expectations of a better life among people with a lower socioeconomic position, and therefore induce higher levels of frustration and stress $[107,108]$.

Finally, social capital in Eastern Europe has received a fair amount of scholarly attention, also in the Czech Republic [109]. Fidrmuc and Gerxhani [110] conclude that the low average stock of social capital in Central and Eastern European countries can be attributed to the lower level of economic development and the lower quality of institutions in the new member countries. The study compared levels of social capital in the Czech Republic with average levels of both old and new EU member states and with neighboring states. Slovakia (which together with the Czech Republic formed Czechoslovakia until its dissolution in 1993), Poland and East Germany represented the "post-communist countries", whereas West-Germany and 
Austria were labeled as "old EU member states". They found that social capital in the Czech Republic (measured by a large set of participation indicators) seems to be closer to the average values of the old EU member states than to the new member states. On the other hand, the generalized social trust value from the 1990 and 1999 World Values Survey were closer to the values of other Eastern European countries than to Western ones. The discrepancy between structural and social capital appears to be an indicator of two important aspects of the Czech society: (1) the fact that structural social capital is closer to the levels observed in longstanding EU member states could possibly reflect the Czech Republic's status as one of the most developed former Eastern bloc countries in economic terms. (2) The low stock of cognitive social capital however is hypothesized to be indicative of the corruption (a form of negative social capital), which was found to be higher than the economic performance would suggest [111]. Fidrmuc and Gerxhani [110] found the same pattern for different measures of altruism. Previous results concerning the interrelationships between cognitive social capital and health inequalities in the Czech Republic did not support any major differences with other Anglo-Saxon (e.g. [60, 66-68]) and Bismarckian countries (e.g. [15]).

\section{Weaknesses}

Despite the use of hierarchical multilevel modeling techniques, we did not control for the contextual dimension of social capital. This is problematic for several reasons. First, several key authors $[112,113]$ stress the cross-level nature of area or place effects in multilevel investigations on social capital and population health and by extension contextual effects in social epidemiology [114]. Confounding from compositional factors, i.e. to separate the influence from individual characteristics of the people who live in certain communities and characteristics of the communities, is of major importance in studies of contextual associations [115]. This problem is especially pertinent to measures of cognitive social capital [112], whereby the contextual variable is the aggregated version of the individual responses [116]. Second, the present analytical approach does not add to the theoretical discussion regarding the level of aggregation of social capital - both for structural and cognitive components - in relation to health and well-being outcomes (e.g. [112, 117-120]). Third, the current analytical treatment of social capital limits the comparability with other work on social capital and health inequalities that considered multiple levels of aggregation (e.g. [15, 67]). Another weakness is the limited generalizability of the results given the specific (cultural) context of the Czech Republic. Moreover, this study applied two measures to capture socioeconomic status, i.e. FAS and relative family wealth. Current scientific evidence acknowledges the complexity of the SES construct and recognizes that a multiple measure approach is required to capture its full complexity [121-123]. Nevertheless, what this approach should look like has so far not been identified and as such, the current approach is quite likely suboptimal.

\section{Strengths}

The most important strength of the study was the introduction of a unique dataset. In general, the understanding of social capital in Eastern Post-communist countries is largely focused on participation levels and institutional measures in relation to corruption [110]. Very little is known about social capital among young people. As the previous Czech HBSC surveys implemented in 1994, 1998, 2002, and 2006 did not include measures of social capital, the 2010 survey was the first opportunity to perform analyses.

\section{Conclusion}

Young peoples' experiences can impact their well-being and have long-term consequences [6]. Positive exposures in early life can bolster a child and young person's longterm well-being, and help them build a 'capital reserve' that can be of benefit throughout life, whereas negative exposures can undermine this. The present findings suggest that cognitive social capital acts as an unequal health resource for adolescents, but could potentially represent opportunities for public health policy to close the gap in socioeconomic disparities.

\section{Endnotes}

${ }^{1}$ Gini coefficients for the Czech Republic, Denmark, Finland, Norway, and Sweden were respectively 0.26, $0.25,0.26,0.25$ and 0.26 .

\section{Abbreviations \\ CFI: Comparative fit index; EU: European Union; FAS: Family affluence scale; HBSC: Health Behaviour in School-aged Children; ICC: Intraclass correlation coefficient; RMSEA: Root Mean Square Error of Approximation; SES: Socioeconomic status; SWB: Subjective well-being; WHO: World Health Organization}

\section{Acknowledgments \\ Special thanks to Dr. Petr Sadílek and the INRES agency who helped to collected the data for this study.}

\section{Funding}

This work was supported by the Ministry of Education, Youth and Sports (MEYS) under contracts No. LG14042 and No. LG 14043.

\section{Authors' contributions}

All authors were involved in the design of the study, contributed to the interpretation of the findings, critically revised the different versions of the manuscript and approved the final version. Additionally to these tasks, TB and JVD performed the statistical analysis and composed the first draft. BDC supervised and coordinated the study. All authors read and approved the final manuscript.

Competing interests

The authors declare that they have no competing interests. 


\section{Consent for publication}

Not applicable.

\section{Ethics approval and consent to participate}

Participation in the study was fully voluntary and anonymous with no explicit incentives provided for participation. Parents were informed about the study from the school administration and could opt out if they disagreed. Data collection was done under the principles of legal and regulatory requirements applicable in the Czech Republic.

\section{Availability of data and materials}

The dataset supporting the conclusions of this article is available in the Research Gate repository, http://dx.doi.org/10.13140/RG.2.2.18678.19529.

\section{Author details}

Unit Health Promotion, Department of Public Health, Ghent University, De Pintelaan 185, K3, B-9000 Ghent, Belgium. ${ }^{2}$ Institute of Active Lifestyle, Faculty of Physical Culture, Palacky University in Olomouc, Tr. Miru 15, Olomouc 77111, Czech Republic. ${ }^{3}$ Department of Psychology, Faculty of Arts, Charles University in Prague, Ovocný trh 3-5, 11636 Praha 1, Czech Republic. ${ }^{4}$ EuroHealthNet, 67 rue de la Loi B-1040, Brussels, Belgium. ${ }^{5}$ School of Medicine, Medical \& Biological Sciences, University of St. Andrews, North Haugh, St Andrews KY16 9TF, UK.

\section{Received: 11 January 2016 Accepted: 1 December 2016} Published online: 12 December 2016

\section{References}

1. Marmot M, Friel S, Bell R, Houweling TA, Taylor S. Closing the gap in a generation: health equity through action on the social determinants of health. Lancet. 2008;372(9650):1661-9.

2. Marmot M, Stansfeld S, Patel C, North F, Head J, White I, Brunner E, Feeney A, Smith GD. Health inequalities among British civil servants: the Whitehall II study. Lancet. 1991;337(8754):1387-93.

3. Mackenbach JP, Stirbu I, Roskam AJR, Schaap MM, Menvielle G, Leinsalu M, Kunst AE, European Union Working Grp S. Socioeconomic inequalities in health in 22 European countries. N Engl J Med. 2008;358(23):2468-81.

4. Viner RM, Ozer EM, Denny S, Marmot M, Resnick M, Fatusi A, Currie C. Adolescence and the social determinants of health. Lancet. 2012; 379(9826):1641-52.

5. Elgar FJ, Pfortner TK, Moor I, De Clercq B, Stevens GW, Currie C. Socioeconomic inequalities in adolescent health 2002-2010: a time-series analysis of 34 countries participating in the Health Behaviour in School-aged Children study. Lancet. 2015;385(9982):2088-95.

6. Stegeman I, Barbareschi G, Costongs C. Chapter 1: Health inequalities among children, young people and families in the EU. In: Stegeman I, Costongs $C$, editors. The Right Start to a Healthy Life Levelling-up the Health Gradient Among Children, Young People and Families in the European Union - What Works? . edn. Brussles: EuroHealthNet; 2012.

7. Pillas D, Suhrcke M. Assessing the potential or actual impact on health and health inequalities of policies aiming to improve early child development (ECD) in England. Background Report to Marmot Review. 2009.

8. Poulton R, Caspi A, Milne BJ, Thomson WM, Taylor A, Sears MR, Moffit TE. Association between children's experience of socioeconomic disadvantage and adult health: a life-course study. Lancet. 2002;360:1640-5

9. Marmot M, Allen J, Goldblatt P, Boyce T, McNeish D, Grady M. Fair society, healthy lives: A strategic review of health inequalities in England post-2010. London: University College London; 2010.

10. Aneshensel CS, Sucoff CA. The neighborhood context of adolescent mental health. J Health Soc Behav. 1996:37:293-310.

11. Mechanic D. Promoting health. Society. 1990;Jan/Feb:16-22.

12. McPherson K, Kerr S, McGee E, Morgan A, Cheater F, McLean J, Egan J. The association between social capital and mental health and behavioural problems in children and adolescents: an integrative systematic review. BMC Psychol. 2014:2(1):7.

13. Marmot M. Status syndrome: how your social standing directly affects your health and life expectancy. London: Bloomsbury; 2004.

14. Solar O, Irwin A. A conceptual framework for action on the social determinants of health. Social Determinants of Health Discussion Paper 2 (Policy and Practice). Geneva: World Health Organization; 2010.
15. De Clercq B, Vyncke V, Hublet A, Elgar FJ, Ravens-Sieberer U, Currie C, Hooghe M, leven A, Maes L. Social Capital and Social Inequality in Adolescents' Health in 601 Flemish Communities: a Multilevel Analysis. Soc Sci Med. 2012;74:202-10.

16. De Clercq B, Pfoertner TK, Elgar FJ, Hublet A, Maes L. Social capital and adolescent smoking in schools and communities: a cross-classified multilevel analysis. Soc Sci Med. 2014;119:81-7.

17. Islam MK, Merlo J, Kawachi I, Lindstrom M, Gerdtham UG. Social capital and health: Does egalitarianism matter? A literature review. Int J Equity Health. 2006;5(5):3.

18. Bourdieu P. The forms of capital. New York: Greenwood Press; 1986

19. Coleman JS. Social Capital in the Creation of Human Capital. Am J Sociol. 1988:94:95-120.

20. Putnam R. Bowling alone: America's declining social capital. J Democr. 1995;6(1):65-78

21. Baum FE, Ziersch AM. Social capital. J Epidemiol Community Health 2003:57(5):320-3.

22. Harpham T, Grant E, Thomas E. Measuring social capital within health surveys: Key issues. Health Policy Plan. 2002;17(1):106-11.

23. Szreter S, Woolcock A. Health by association? Social capital, social theory and the political economy of public health. Int J Epidemiol. 2004;33(4):650-67.

24. Kim D, Subramanian SV, Kawachi I. Social capital and physical health: a systematic review of the literature. In: Kawachi I, Subramanian SV, Kim D, editors. Social capital and health. edn. New York: Springer; 2008. p. 139-90.

25. Hawe P, Schiell A. Social capital and health promotion: A review. Soc Sci Med. 2000:51(6):871-85.

26. De Silva MJ, McKenzie K, Harpham T, Huttly SRA. Social capital and mental illness: a systematic review. J Epidemiol Community Health. 2005;59(8):619-27.

27. Almedon AM, Glandon D. Social capital and mental health: an updated interdisciplinary review of primary evidence. In: Kawachi I, Subramanian SV, Kim D, editors. Social capital and health. edn. New York: Springer; 2008. p. 191-214

28. Lindström M. Social capital and health related behaviours. In: Kawachi I, Subramanian SV, Kim D, editors. Social capital and health. edn. New York: Springer; 2008. p. 215-38.

29. Cagney KA, Wen M. Social capital and aging-related outcomes. In: Kawachi I Subramanian SV, Kim D, editors. Social capital and health. edn. New York: Springer; 2008. p. 239-58.

30. Macinko J, Starfield B. The Utility of Social Capital in Research on Health Determinants Milbank O 2001·79(3):387-427.

31. Kawachi I, Subramanian SV. Neighbourhood influences on health J Epidemiol Community Health. 2007;61:3-4

32. Subramanian SV. The relevance of multilevel statistical methods for identifying causal neigborhoods effects. Soc Sci Med. 2004:58:1961-7.

33. Park N. The Role of Subjective Well-Being in Positive Youth Development. Ann Am Acad Pol Soc Sci. 2004:591(1):25-39.

34. Bowers EP, Li YB, Kiely MK, Brittian A, Lerner JV, Lerner RM. The Five Cs Model of Positive Youth Development: A Longitudinal Analysis of Confirmatory Factor Structure and Measurement Invariance. J Youth Adolesc. 2010:39(7):720-35.

35. Morgan A, Haglund BJ. Social capital does matter for adolescent health: evidence from the English HBSC study. Health Promot Int. 2009;24(4):363-72.

36. Helliwell JF. Well-being and social capital: Does suicide pose a puzzle? Soc Indic Res. 2007:81(3):455-96.

37. Diener E, Chan MY. Happy People Live Longer: Subjective Well-Being Contributes to Health and Longevity. Appl Psychol Health Well Being. 2011;3(1):1-43.

38. Diener E, Oishi S, Lucas RE. Subjective Well-Being: The Science of Happiness and Life Satisfaction. In: Snyder CR, Lopez SJ, editors. The Oxford Handbook of Positive Psychology, (2 Ed). New York: Oxford University Press; 2012. p. 117-33.

39. Valois RF, Zullig KJ, Huebner ES, Drane JW. Physical activity behaviors and perceived life satisfaction among public high school adolescents. J Sch Health. 2004:74(2):59-65.

40. lannotti RJ, Kogan MD, Janssen I, Boyce WF. Patterns of adolescent physical activity, screen-based media use, and positive and negative health indicators in the U.S. and Canada. J Adolesc Health. 2009;44(5):493-9. 
41. Desousa C, Murphy S, Roberts C, Anderson L. School policies and binge drinking behaviours of school-aged children in Wales-a multilevel analysis. Health Educ Res. 2008;23(2):259-71.

42. van Kooten $M$, de Ridder D, Vollebergh W, van Dorsselaer S. What's so special about eating? Examining unhealthy diet of adolescents in the context of other health-related behaviours and emotional distress. Appetite. 2007;48(3):325-32

43. Kuntsche E, Rehm J, Gmel G. Characteristics of binge drinkers in Europe. Soc Sci Med. 2004;59(1):113-27.

44. Molcho M, Gabhainn SN, Kelly C, Friel S, Kelleher C. Food poverty and health among schoolchildren in Ireland: findings from the Health Behaviour in School-aged Children (HBSC) study. Public Health Nutr. 2007;10(4):364-70.

45. Levin KA, Torsheim T, Vollebergh W, Richter M, Davies CA, Schnohr CW, Due P, Currie C. National Income and Income Inequality, Family Affluence and Life Satisfaction Among 13 year Old Boys and Girls: A Multilevel Study in 35 Countries. Soc Indic Res. 2011;104(2):179-94.

46. Conger RD, Conger KJ, Martin MJ. Socioeconomic Status, Family Processes, and Individual Development. J Marriage Fam. 2010;72(3):685-704.

47. Cantrill $H$. The pattern of human concerns. New Brunswick: Rutgers University Press; 1965.

48. Diener E. Subjective well-being. The science of happiness and a proposal for a national index. Am Psychol. 2000;55(1):34-43.

49. Helliwell JF. Social capital, the economy and wellbeing. In: Banting K, Sharpe A, St-Hilaire F, editors. The review of economic performance and social progress. Montreal and Ottawa: Institute for Researchon Public Policy and Centre for the Study of Living Standards; 2001. p. 43-60.

50. Donovan N, Halpern D, Sargeant R. Life satisfaction: the state of knowledge and implications for government. London: Cabinet Office Strategy Unit; 2003.

51. Bjørnskov C. Social capital and happiness in the United States. Appl Res Qual Life. 2008;3:43-62.

52. Klein C. Social capital or social cohesion: What matters for subjective well-being (SWB)? EPS/INSTEAD working paper. 2011. p. 2011-36.

53. Lau M, Li W. The extent of family and school social capital promoting positive subjective well-being among primary school children in Shenzhen, China. Child Youth Serv Rev. 2011;33(9):1573-82.

54. Nielsen L, Koushede V, Vinther-Larsen M, Bendtsen P, Ersboll AK, Due P, Holstein BE. Does school social capital modify socioeconomic inequality in mental health? A multi-level analysis in Danish schools. Soc Sci Med. 2015;140:35-43.

55. Pfortner TK, De Clercq B, Lenzi M, Vieno A, Rathmann K, Moor I, Hublet A, Molcho M, Kunst AE, Richter M. Does the association between different dimension of social capital and adolescent smoking vary by socioeconomic status? a pooled cross-national analysis. Int J Public Health. 2015;60(8):901-10.

56. Drukker M, Kaplan C, Feron F, van Os J. Children's health-related quality of life, neighbourhood socio-economic deprivation and social capital. A contextual analysis. Soc Sci Med. 2003;57(5):825-41.

57. Boyce WF, Davies D, Gallupe O, Shelley D. Adolescent risk taking, neighborhood social capital, and health. J Adolesc Health. 2008;43(3):246-52.

58. Mackinnon DP, Luecken LJ. How and for whom? Mediation and moderation in health psychology. Health Psychol. 2008;27(2):S99-100.

59. Fairchild AJ, MacKinnon DP. A General Model for Testing Mediation and Moderation Effects. Prev Sci. 2009;10(2):87-99.

60. Veenstra G. Social capital, SES and health: An individual-level analysis. Soc Sci Med. 2000;50(5):619-29.

61. Dahl E. Social inequality and health: the role of social capital. Sociol Health IIIn. 2010;32(7):1102-19.

62. Lindström M, Hanson BS, Ostergren P-O. Socioeconomic differences in leisure-time physical activity: the role of social participation and social capital in shaping health related behaviour. Soc Sci Med. 2001;52:441-51.

63. Vyncke V, De Clercq B, Stevens V, leven A, Hrafn Jonsson S, Darias Curvo S, Kebza V, Currie C, Maes L. Does neighborhood social capital make a difference for levelling the health gradient in children? A literature review. 2013. In press.

64. Xue Y, Leventhal T, Brooks-Gunn J, Earls FJ. Neighborhood residence and mental health problems of 5- to 11-year-olds. Arch Gen Psychiatry. 2005;62:554-63.

65. Kohen DE, Leventhal T, Dahinten VS, McIntosh CN. Neighborhood disadvantage: pathways of effects for young children. Child Dev. 2008;79(1):156-69.

66. Caughy $\mathrm{MO}$, Nettles SM, O'Campo PJ. The effect of residential neighborhood on child behavior problems in first grade. Am J Community Psychol. 2008:42:39-50.
67. Odgers CL, Moffitt TE, Tach LM, Sampson RJ, Taylor A, Matthews CL, Caspi A. The Protective Effects of Neighborhood Collective Efficacy on British Children Growing Up in Deprivation: A Developmental Analysis. Dev Psychol. 2009;45:942-57.

68. Elgar FJ, Trites SJ, Boyce W. Social capital reduces socioeconomic differences in child health: evidence from the Canadian Health Behaviour in School-aged Children study. Can J Public Health. 2010;101(3):23-7.

69. Eikemo TA, Huiseman M, Bambra C, Kunst AE. Health inequalities according to educational level in different welfare regimes: a comparison of 23 European countries. Soc Health Illness. 2008;30(4):565-82.

70. Eikemo TA, Bambra C, Joyce K, Dahl E. Welfare state regimes and income-related health inequalities: a comparison of 23 European countries. Eur J Pub Health. 2008;18(6):593-9.

71. Eikemo TA, Bambra C. The welfare state: a glossary for public health. J Epidemiol Community Health. 2008;62(1):3-6.

72. Richter M, Rathman K, Gabhainn SN, Zambon A, Boyce W, Hurrelmann K. Welfare state regimes, health and health inequalities in adolescence: a multilevel study in 32 countries. Soc Health Illness. 2012;34(6):1-22.

73. Dahl E, Lorentzen T, Flotten T. Poverty dynamics and social exclusion in Norway. J Soc Policy. 2008;37(2):231-49.

74. Fujisawa Y, Hamano T, Takegawa S. Social capital and perceived health in Japan: an ecological and multilevel analysis. Soc Sci Med. 2009;69:500-5.

75. Esping-Andersen G. Social Foundations of Postindustrial Economies. Oxford: Oxford University Press; 1999.

76. OECD. OECD Factbook 2011: Economic, Environmental and Social Statistics. 2011

77. Bjornkov C. The happy few: cross-country evidence on social capital and life satisfaction. Kyklos. 2003;56(1):3-16.

78. Esping-Andersen $\mathrm{G}$. The three worlds of welfare capitalism. Cambridge: Polity; 1990.

79. Kääriänen J, Lehtonen $H$. The variety of social capital in welfare state regimes - a comparative study of 21 countries. Eur Soc. 2006;8(1):25-57.

80. Korpi W, Palme J. The paradox of redistribution and strategies of equality: welfare state institutions, inequality, and poverty in the western countries. Am Sociol Rev. 1998;63(5):661-88.

81. Rothstein B. Social capital in the social democratic welfare state. Politics Soc. 2001;29(2):207-41

82. Currie C, Nic Gabhainn S, Godeau E, Committee tIHNC. The Health Behaviour in School-aged Children: WHO Collaborative Cross-National (HBSC) Study: origins, concept, history and development 1982-2008. Int J Public Health. 2009;54:131-9.

83. Roberts C, Candace C, Samdal O, Currie D, Smith R, Maes L. Measuring the health and health behaviours of adolescents through cross-national survey research: recent developments in the health behavior in School-aged Children (HBSC) study. J Public Health. 2007;15:179-86.

84. Currie C, Elton RA, Todd J, Platt S. Indicators for socio-economic status for adolescents: the WHO Health Behaviour in School-aged Children Survey. Health Educ Res. 1997;12:385-97.

85. Currie C, Molcho M, Boyce W, Holstein B, Torsheim T, Richter M. Researching health inequalities in adolescents: the development of the Health Behaviour in School-Aged Children (HBSC) family affluence scale. Soc Sci Med. 2008;66(6):1429-36.

86. Andersen A, Krølner R, Currie C, Dallago L, Due P, Richter M, Orkényi A, Holstein B. High agreement on family affluence between children's and parents' reports: international study of 11-year-olds. J Epidemiol Community Health. 2008;62(12):1092-4.

87. Currie C, Samdal O, Boyce W, Smith R. Health Behaviour in School-aged Children: a WHO Cross-National Study (HBSC), Research Protocol for the 2001/2002 Survey. Edinburgh: Child and Adolescent Health Research Unit (CAHRU), University of Edinburgh; 2001.

88. Muthén LK, Muthén BO. Mplus User's Guide. Sixth Edition. Los Angeles, CA: Muthén \& Muthén; 1998-2011.

89. Rasbash J, Steele F, Browne WJ, Goldstein H. A User's Guide to MLwiN, V2.1: Centre for Multilevel Modelling, University of Bristol.; 2009.

90. Hox J. Multilevel Analysis. Techniques and Applications. 2nd ed. New York: Routledge; 2010.

91. Goldstein H. Multilevel statistical models. 3rd ed. London: Hodder Arnold; 2003.

92. Mackinnon DP. Introduction to Statistical Mediation Analysis. New York: Lawrence \& Erlbaum Associates; 2008. 
93. Sobel ME. Asymptotic confidence intervals for indirect effects in structural equations models. In: Leinhart S, editor. Sociological Methodology 1982. edn. San Francisco: Jossey-Bass; 1982. p. 290-312.

94. Baum FE. Social capital: is it good for your health? Issues for a public health agenda. J Epidemiol Community Health. 1999;53:195-6.

95. Lynch J, Due P, Muntaner C, Davey Smith G. Social capital - Is it a good investment strategy for public health? J Epidemiol Community Health. 2000;54:404-8.

96. Wilkinson RG. Inequality and the social environment: a reply to Lynch et al. J Epidemiol Community Health. 2000;54:411-3.

97. Ferlander $\mathrm{S}$. The importance of different forms of social capital for health. Acta Sociologica. 2007;50(2):115-28.

98. Fujiwara T, Kawachi I. A prospective study of individual-level social capital and major depression in the United States. J Epidemiol Community Health. 2008;62:627-33

99. Rodriguez-Pose A, von Berlepsch V. Social Capital and Individual Happiness in Europe. J Happiness Stud. 2014;15(2):357-86.

100. Puntscher S, Hauser C, Walde J, Tappeiner G. The Impact of Social Capital on Subjective Well-Being: A Regional Perspective. J Happiness Stud. 2015;16(5):1231-46.

101. Frey BS, Stutzer A. Happiness and economics : how the economy and institutions affect well-being. Princeton: Princeton University Press; 2001.

102. Elgar FJ, De Clerca B, Schnohr CW, Bird P, Pickett KE, Torsheim T, Hofmann F, Currie C. Absolute and relative family affluence and psychosomatic symptoms in adolescents. Soc Sci Med. 2013;91:25-31.

103. Kawachi I, Berkman LF. Social cohesion, social capital and health. In: Berkman LF, Kawachi I, editors. Social epidemiology, edn. New York: Oxford University Press; 2000.

104. Pearce N, Davey Smith G. Is social capital the key to inequalities in health? Am J Public Health. 2003;93(1):122-9.

105. Mackenbach JP. The persistence of health inequalities in modern welfare states: The explanation of a paradox. Soc Sci Med. 2012;75:761-9.

106. Sjoberg O. Social insurance as a collective resource: unemployment benefits, job insecurity and subjective well-being in a comparative perspective. Social Forces. 2010;88:1281-304.

107. Wilkinson RG, Pickett $K$, editors. The Spirit Level. Why Equality is Better for Everyone. London: Penguin; 2009.

108. Dahl E, Fritzell J, Lahelma E, Martikainen P, Kunst AE, Mackenbach JP. Welfare state regimes and health inequalities. In: Siegrist J, Marmot M, editors. Social inequalities in health New evidence and policy implications. edn. Oxford/New York: Oxford University Press; 2006.

109. Vodrazka M. Social capital in the Czech Republic and public policy implications. Cent Eur J Public Policy. 2009;3(1):66-87.

110. Fidrmuc J, Gërxhani K. Mind the gap! Social capital, East and West. Working paper no. 07-10. Uxbridge: Brunel University, Centre for Economic Development \& Institutions; 2007.

111. Vodrážka M. Social Capital in the Czech Republic and Public Policy Implications. Cent Eur J Public Policy. 2009;3(1):22.

112. Subramanian SV, Kim D, Kawachi I. Social Trust and Self-Rated Health in US Communities: a Multilevel Analysis. J Urban Health. 2002;79(4):21-34.

113. Kawachi I, Kim D, Coutts A, Subramanian SV. Commentary: Reconciling the tree accounts of social capital. Int J Epidemiol. 2004;33:682-90.

114. Diez Roux AV. Bringing context back into epidemiology: variables and fallacies in multilevel analysis. Am J Public Health. 1998;88:216-22.

115. Duncan C, Jones K, Moon G. Context, composition and heterogeneity: using multilevel models in health research. Soc Sci Med. 1998;1:97-117.

116. Diez Roux AV. Investigating Neighborhood and Area Effects on Health. Am J Public Health. 2001;91(11):1783-9.

117. Subramanian SV, Lochner K, Kawachi I. Neighborhood differences in social capital: a compositional artifact or a contextual construct? Health Place. 2003;9:33-44

118. Poortinga W. Social capital: An individual or collective resource for health? Soc Sci Med. 2006;62(2):292-302.

119. Poortinga W. Social relations or social capital? Individual and community health effects of bonding social capital. Soc Sci Med. 2006;63:255-70.

120. Poortinga W. Community resilience and health: The role of bonding, bridging, and linking aspects of social capital. Health Place. 2012;18:286-95.

121. Potter BK, Speechley KN, Gutmanis IA, Campbell MK, Koval JJ, Manuel D. A comparison of measures of socioeconomic status for adolescents in a Canadian national health survey. Chronic Dis Can 2005;26(2-3):80-9.
122. Pfortner TK, Guenther S, Levin KA, Torsheim T, Richter M. The use of parental occupation in adolescent health surveys. An application of ISCO-based measures of occupational status. J Epidemiol Community Health. 2015;69(2):177-84.

123. Elgar FJ, McKinnon B, Torsheim T, Schnohr CW, Mazur J, Cavallo F, Currie C. Patterns of Socioeconomic Inequality in Adolescent Health Differ According to the Measure of Socioeconomic Position. Soc Indic Res. 2016;127(3):1169-80.

\section{Submit your next manuscript to BioMed Central and we will help you at every step:}

- We accept pre-submission inquiries

- Our selector tool helps you to find the most relevant journal

- We provide round the clock customer support

- Convenient online submission

- Thorough peer review

- Inclusion in PubMed and all major indexing services

- Maximum visibility for your research

Submit your manuscript at www.biomedcentral.com/submit 